\title{
ANÁLISIS DE LAS FUERZAS COMPETITIVAS DE PORTER EN EL SECTOR DE PROMOCIÓN INMOBILIARIA DEL GRAN SANTO DOMINGO
}

Analysis of the competitive forces of Porter in the property development sector of the great Santo Domingo

\section{Luz Then Solange Pimentel Paola Olivero Ailec Soto Abraham Luna Gilbert Cruz Miguel Peguero Carlos Jáquez Jorge Lluberes ${ }^{1}$}

Resumen: Esta investigación ${ }^{2}$ busca elaborar el primer análisis de cinco fuerzas para conocer la situación actual del mercado inmobiliario; se pretende que sirva como herramienta para tomar decisiones con relación a la inversión del sector inmobiliario y que sirva como base para futuras investigaciones científicas y para la creación de metodologías de ingreso. El objetivo primordial de este análisis es identificar cómo se comportan las cinco fuerzas

Todos los autores son egresados de la carrera de Ingeniería Civil de INTEC.

2 Esta investigación contó con la asesoría intelectual del Dr. Tulio Rodríguez. 
competitivas de Porter. El lugar escogido para la producción de este estudio fue el Gran Santo Domingo (Distrito Nacional y los municipios de la provincia de Santo Domingo: Santo Domingo Este, Santo Domingo Oeste, Santo Domingo Norte, Boca Chica y Los Alcarrizos). Los resultados muestran que la mayor fuerza del sector es la rivalidad entre competidores existentes, esto se debe a la presencia de grandes empresas y a la gran cantidad de empresas en el mercado, eso en primer lugar, en segundo lugar está el aspecto relativo al poder de los compradores es: la fuerza de estos radica en la facilidad de cambios y en la similitud de los productos ofertados. En tercer lugar tenemos el poder de los proveedores, seguido de la amenaza de nuevos entrantes y con menor influencia en el sector y la amenaza de productos sustitutos. Para el estudio también se analizó la llamada sexta fuerza que son los productos complementarios, en este caso, la banca y el gobierno.

Palabras clave: Competitividad, industria de la construcción inmobiliaria, modelo de las Cinco Fuerzas de Porter.

Abstract: This research seeks to elaborate the first Five Forces analysis to get to know the actual situation of the homebuilding market which works like a tool to make decisions respecting to the investments in the area like a base for future scientific investigations and the creation of income methods. The main objective of this analysis is to identify how the 5 forces of Porter behave. The place chosen to produce this study was the Gran Santo Domingo (Distrito Nacional and the places of the Santo Domingo province: Santo Domingo Este, Santo Domingo Oeste, Santo Domingo Norte, Boca Chica y Los Alcarrizos). As a result, the bigger force of the sector is the competitive rivalry, this is because of the presence of big companies and the high quantity of companies in the market. Second, the buyer power, this force lies on the facility of changes and the similarity of the product offered. In third place, we have the supplier power then, the threat of 
new entrants and with less influence the threat of substitute products. In addition, the sixth Force of Porter, that is the complement products, was also analyzed. In this case, those are, the bank and the government.

Keywords: Competitiveness, homebuilding industry, Porter's Five Competitive Forces model.

\section{Introducción}

El presente estudio resume los resultados de un análisis de las cinco fuerzas competitivas de Porter aplicadas al sector de la promoción inmobiliaria en Santo Domingo, República Dominicana. Este artículo fue realizado por un grupo de estudiantes de término de la carrera de Ingeniería Civil del Instituto Tecnológico de Santo Domingo (INTEC), para la asignatura denominada Seminarios de Ingeniería Civil, en el período agosto-diciembre de 2013.

De la misma forma es un instrumento útil para la banca debido a que, con el mismo se podrá discernir a la hora de realizar préstamos hipotecarios y determinar la factibilidad de los proyectos inmobiliarios.

El déficit habitacional existente en el gran Santo Domingo es de 68,000 viviendas. Existe un descrecimiento de un 4\% en el sector construcción y vivienda. Por lo cual es necesario que en esta parte del sector construcción exista un análisis que incentive la creación de una política integral para la construcción habitacional logrando dinamizar el sector. El hecho de conocer las barreras existentes, favorece la creación de metodologías que conduzcan al éxito de los inversionistas y mejora la calidad de vida de la población. 
La investigación busca tener una visualización sobre dónde es propicio colocar su capital mediante una estrategia de división de conglomerado. El objetivo primordial de este análisis es identificar cómo se comportan las cinco fuerzas competitivas de Porter, así como generar un instrumento que disminuya la incertidumbre al momento de invertir en un proyecto inmobiliario. Conjuntamente, la elaboración de un modelo de análisis, replicable en el tiempo del sector inmobiliario de Santo Domingo.

\section{Diseño de investigación}

El presente documento expone un análisis aplicado de las variables que componen y afectan al sector de promoción inmobiliaria. Este análisis se fundamenta en un modelo propuesto por Michael Porter (1980), conocido como el "Modelo de las cinco fuerzas". Este modelo estudia las características propias de un negocio, en nuestro caso, un sector, obteniendo el comportamiento del mismo.

Las cinco fuerzas del modelo clásico de Porter son: competidores potenciales, productos sustitutos, rivalidad en el mercado, poder del comprador y poder del proveedor. En el artículo se tomó en cuenta la llamada sexta fuerza, los "complementarios", en este caso se contemplaron como complementarios: la banca y el gobierno.

\section{Alcance}

El lugar escogido para la producción de este estudio fue el Gran Santo Domingo (Distrito Nacional y los municipios de la provincia de Santo Domingo: Santo Domingo Este, Santo Domingo Oeste, Santo Domingo Norte, Boca Chica y Los Alcarrizos). 


\section{Población y muestra}

Según el listado de la Dirección General de Impuestos Internos en el país hay un universo de 17,423 empresas constructoras y promotoras en República Dominicana, lo cual arroja una muestra de 264, la población de constructoras de Santo Domingo es de 11,423 lo cual en proporción al universo arroja una muestra de 173. Durante la realización de las encuestas se evidenció que un gran porcentaje de estas compañías no están funcionando o ya no existen, por esta razón la muestra se redujo a un total de 132 empresas. Las empresas a la vez dividida en 120 para el instrumento cerrado de autoría propia, validado por un grupo control de 32 profesionales dedicados al sector y 12 entrevistas.

\section{Marco legal}

La ley que regula el sector inmobiliario en República Dominicana es la Ley N. ${ }^{\circ} 108-05$ de Registro Inmobiliario, también la Ley N. ${ }^{\circ} 189-11$ sobre Desarrollo del Mercado Hipotecario y Fideicomiso facilita el uso o inversión de los fondos de pensiones en proyectos inmobiliarios de impacto social, lo cual significa un estímulo a los constructores a desarrollar proyectos inmobiliarios que estén dirigidos a sectores de clase media baja.

\section{Análisis del mercado}

DESARROLLO DEL PRODUCTO INTERNO BRUTO EN LA CONSTRUCCIÓN

Durante el primer trimestre del año 2013, la construcción registró una caída dentro del PIB con respecto al promedio del año 2012 de un $3.73 \%$ a un $3.7 \%$, aun así el sector constituye el segundo lugar con mayor aporte al PIB de las diferentes industrias que tiene un total de $26.1 \%$. Mostrando así que es un sector significativo en la base económica del país. 
Luz Then, Solange Pimentel, Paola Olivero, Ailec Soto, Abraham Luna, Gilbert Crur, Miguel Peguero, Carlos Jáquez, Jorge Lluberes

Figura N. ${ }^{\circ} 1$

Promedio del PIB del 2010-2013

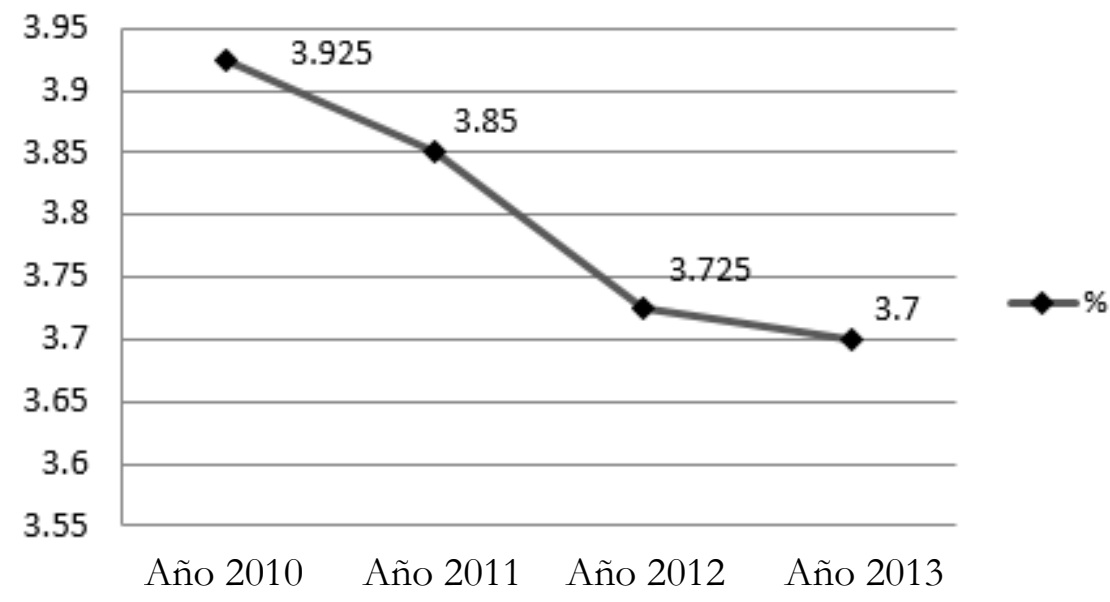

Fuente: Banco Central de la República Dominicana

Figura N. ${ }^{\circ} 2$

Préstamos hipotecarios realizados desde el 2006 a julio del 2013 en la República Dominica

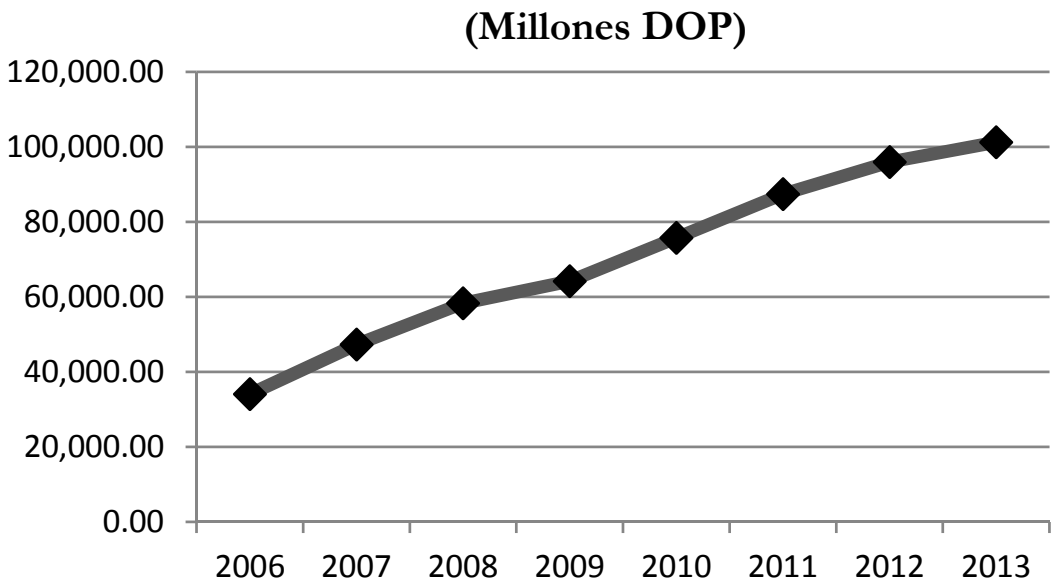

Fuente: Superintendencia de Bancos de la República Dominicana 
Análisis de las Fuerzas Competitivas de Porter en el sector de promoción inmobiliaria del Gran Santo Domingo

\section{Figura N. ${ }^{\circ} 3$}

Créditos hipotecarios, cantidad de préstamos 2006/2013

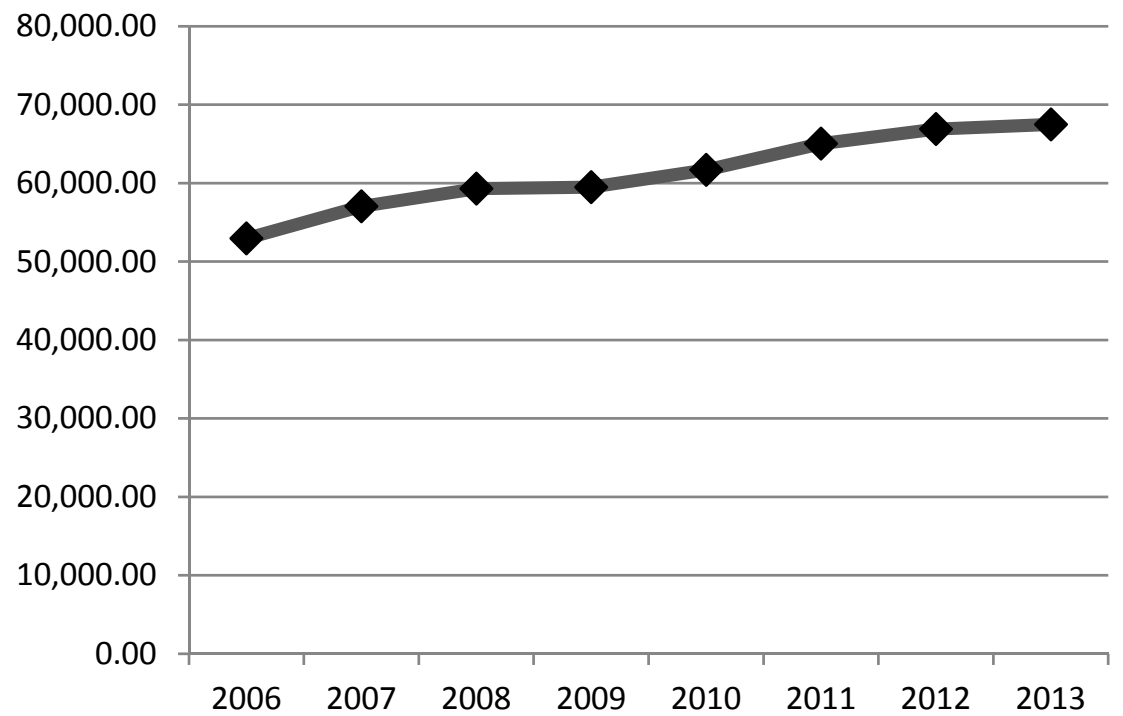

Fuente: Superintendencia de Bancos de la República Dominicana

\section{VOLUMEN DEL MERCADO}

Inversión extranjera en el sector inmobiliario de la República Dominicana

Representado esta $12.4 \%$ de todas la inversión extranjera en el país en diferentes actividades. Representado la 4ta. actividad con mayor inversión. 
Luz Then, Solange Pimentel, Paola Olivero, Ailec Soto, Abraham Luna, Gilbert Cruz, Miguel Peguero, Carlos Jáquez, Jorge Lluberes

\section{Figura N. ${ }^{\circ} 4$}

Flujo de la inversión extranjera directa inmobiliaria

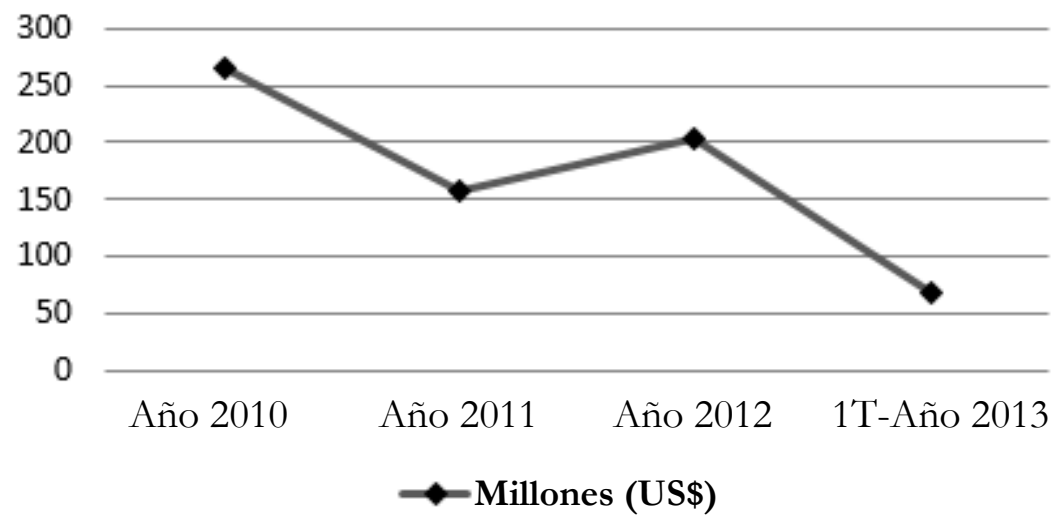

Fuente: Banco Central de la República Dominicana

INVERSIÓN DEL SECTOR PRIVADO EN LA CONSTRUCCIÓN

La Oficina Nacional de Estadísticas ONE realizó un documento para evaluar algunos puntos dentro del sector construcción como los que serán mencionados a continuación:

1. Números de permisos otorgados para la construcción en el sector privado, por tipo de construcción, según mes (2010).

- Apartamentos o edificios 474 permisos

- Viviendas 239 permisos

2. Inversión en construcción del sector privado, por tipo de construcción, según mes (2010). En (miles de RD\$)

- Apartamentos o edificios $\quad 6,864,124.13$

- Viviendas

$379,751.15$

ANÁLISIS CINCO FUERZAS

A continuación se presenta un análisis de los resultados obtenidos de las encuestas realizadas a ingenieros de compañías del gran Santo Domingo. 
Análisis de las Fuerzas Competitivas de Porter en el sector de promoción inmobiliaria del Gran Santo Domingo

\section{Figura N. ${ }^{\circ} 5$ \\ Rivalidad entre competidores}

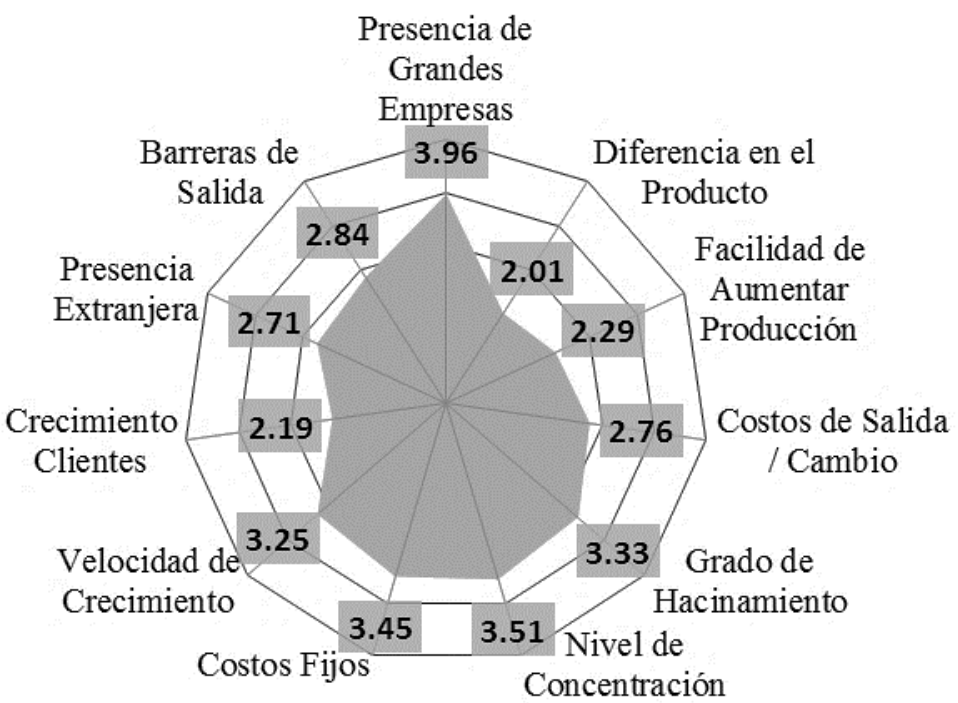

\section{Clase Alta}

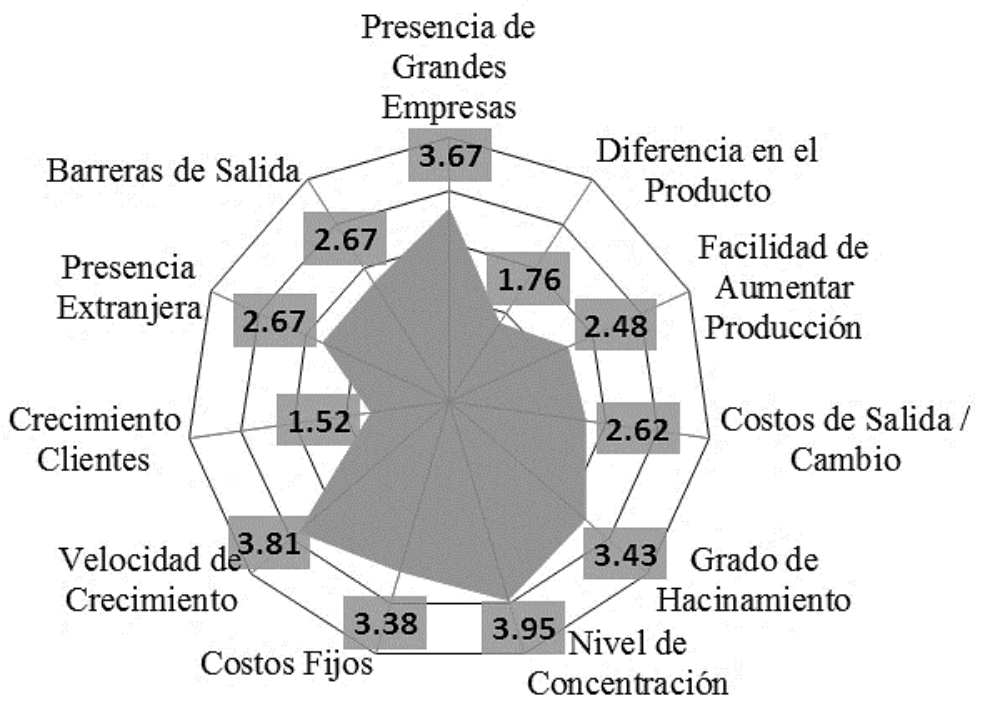

Ciencia y Sociedad 2014; 39(3): 441-476 449 


\section{Clase Media}

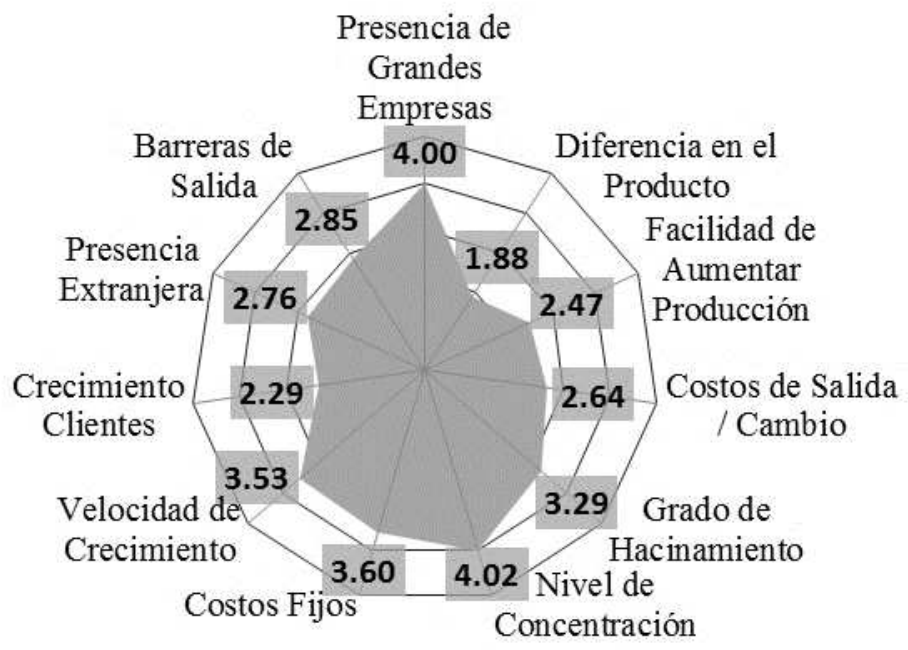

\section{Clase Baja}

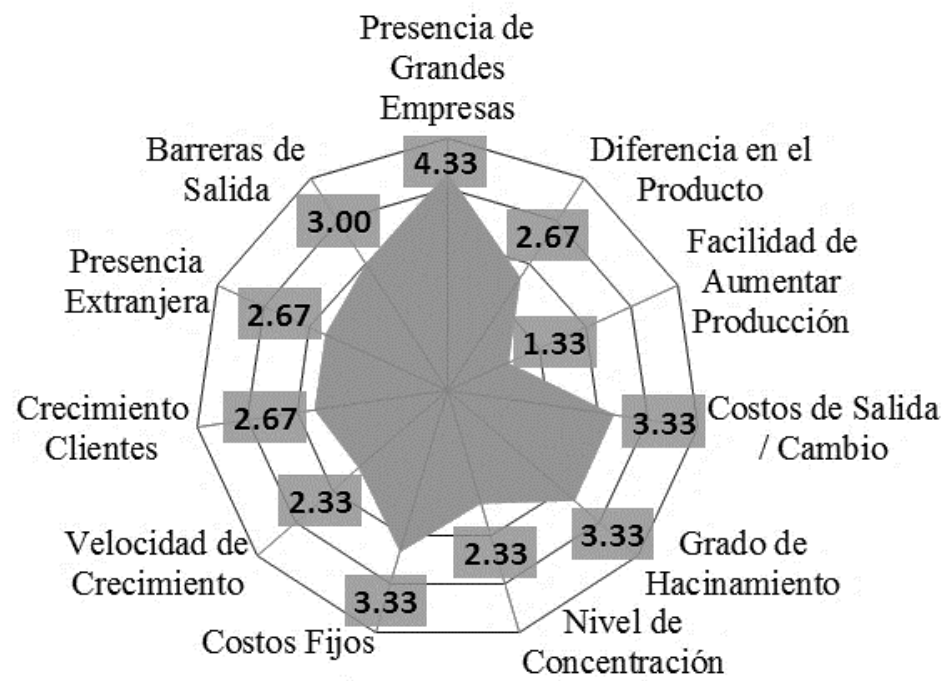

Fuente: Elaboración propia. 
La fuerza de los competidores analiza el nivel de rivalidad del sector. En otras palabras, qué cosas crean o aumentan la rivalidad entre las compañías que forman parte del sector. Parámetros como el posicionamiento de los competidores, los costos fijos que envuelven al sector, que tantos competidores hay, si hay o no guerra de precios, entre otras cosas son los que definen el nivel de rivalidad del sector. Además, se toman en cuenta las situaciones que hacen difícil la salida del sector.

Como puede verse en las gráficas, esta fuerza varía según la clase a la cual se dirige el sector. La clase con el comportamiento más variable es el de clase baja ya que varía de forma general. El aspecto que más rivalidad produce, en todas las clases, es la presencia de grandes empresas compitiendo. Este obtuvo el mayor valor para la clase baja debido a la estrategia de producción en masa que caracteriza a este gremio del sector. La ventaja que tienen estas grandes empresas de mantener los mismos costos fijos para múltiples proyectos y su habilidad de producir en masa, las convierte en una amenaza para el resto. Por la misma razón, para la clase baja, es más fácil aumentar la producción. El segundo aspecto que más rivalidad produce entre las compañías, en el gremio de clase baja, son los altos costos fijos que caracterizan al sector; a diferencia del resto de los gremios donde, el segundo factor es el nivel de concentración. El hecho de que muchas empresas compitan con productos similares es lo que le brinda poder a la fuerza ya que genera guerra de precios y hace que los productos sean de mejor calidad.

El grado de hacinamiento es uno de los aspectos que más poder le da a la fuerza, sin embargo a los que más afecta esta similitud entre empresas y productos ofertados es a la clase baja debido a que a las empresas de este gremio les resulta muy difícil diferenciarse en el producto manteniendo el precio de competencia. Por el hecho de que en este gremio los productos son muy estándares. Aquí reside la explicación del por qué para la clase baja, la diferencia en el producto es mucho mayor que en las otras clases; la velocidad de crecimiento del sector no es en realidad un problema para esta clase. 
En contraste, la velocidad de crecimiento para las otras clases si representa una amenaza ya que este crecimiento los obliga a ofrecer productos con precios más bajos y mejor calidad, generando así una guerra de precios dentro del sector.

El hecho de que la clase alta es un gremio del sector que se caracteriza por presentar altos costos, las altas exigencias, y la minoría de los consumidores, explica por qué el crecimiento en cuanto a clientes tiende a disminuir, según lo observado en los últimos años, la rivalidad dentro de este gremio con relación a los otros.

En suma, la alta competitividad del sector se debe primordialmente a la alta concentración de empresas y la alta influencia que significa la participación de la minoría que representan las grandes empresas. El capital con el que cuentan, las estrategias de producción en masa, integración hacia atrás y hacia adelante que diferencia a este limitado grupo les permite ofrecer precios relativamente bajos. Esto representa una gran amenaza para el resto del sector debido a que deben ajustarse a ofrecer una mejor oferta aceptando menos márgenes de rentabilidad. De la misma forma afectan los negocios ilícitos al sector. El sector de la promoción inmobiliaria es la vía preferida para legalizar el dinero de origen indebido. Como lo primordial en su caso no es recuperar la inversión o si quiera vender, ofrecen precios insólitos con los cuales es difícil competir.

Los costos necesarios para dejar de competir en el sector y salirse son altos. Es por esto que esta barrera mantiene la rivalidad del sector.

El sector de promoción inmobiliario dominicano no ha llegado aún a su punto de máximo desarrollo, lo que significa que hay suficiente espacio para que la gran cantidad de empresas que existen consigan desenvolverse y aprovechen un pedazo cada uno. El hecho de que las empresas en este sector produzcan productos parecidos en general, nos dice que hay que buscar 
desarrollar productos con esta tendencia general pero que destaquen en puntos únicos convirtiéndolos en una atracción para el cliente.

La migración de promotores e inversionistas extranjeros, venezolanos, por ejemplo, que participan en nuestro sector en los últimos años demuestra el recurso sin aprovechar que es el sector de promoción inmobiliario dominicano. En la actualidad, puede considerarse como un sector que no está siendo dinámico si se compara con épocas anteriores a la crisis. Los factores responsables de esta lenta velocidad de desarrollo son rastros de la crisis mundial y local que han impactado la economía dominicana. Entre estos factores se encuentran la desconfianza en el sector y la desconfianza en el cliente mismo. Desconfianza en el sector se refiere a las situaciones observadas según las cuales hay promotoras que no cumplen con la entrega debido a problemas financieros arraigados, a esto se suma el incorrecto e incompleto control de las autoridades y las pobres facilidades que le ofrece el sector de la banca a estos. La desconfianza a la que se alude también atañe a la inseguridad que sienten los clientes ante la economía de los últimos años; miedo a perder el empleo repentinamente, miedo a que el banco decida aumentar insólitamente las tasas de interés, entre otras cosas.

Hay una gran velocidad de crecimiento en el sector en el sentido de que son muchas empresas compitiendo y muchos clientes. Esto incrementa la rivalidad entre los competidores. 


\section{Figura N. ${ }^{\circ} 6$ \\ Poder de los compradores}

\section{Clase Baja}

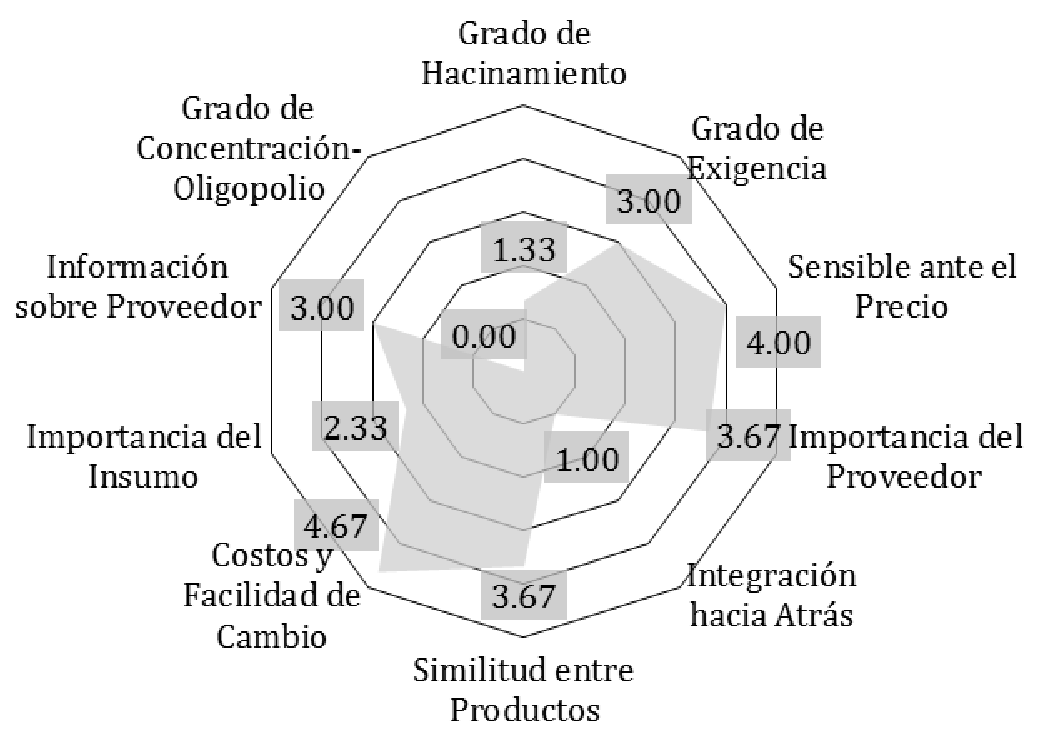

\section{Clase media}

Grado de Hacinamiento

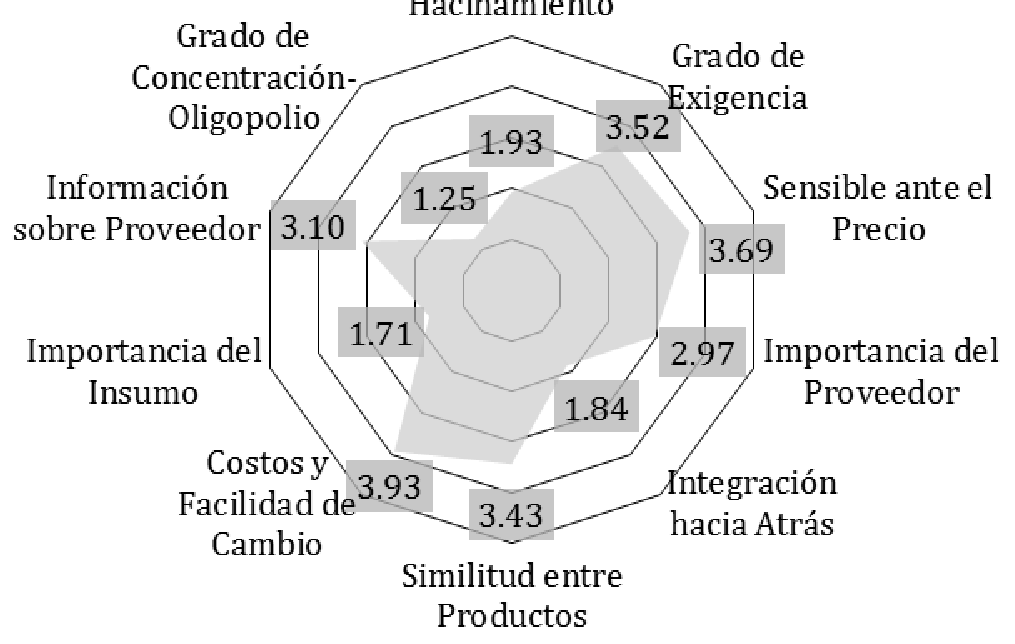


Análisis de las Fuerzas Competitivas de Porter en el sector de promoción inmobiliaria del Gran Santo Domingo

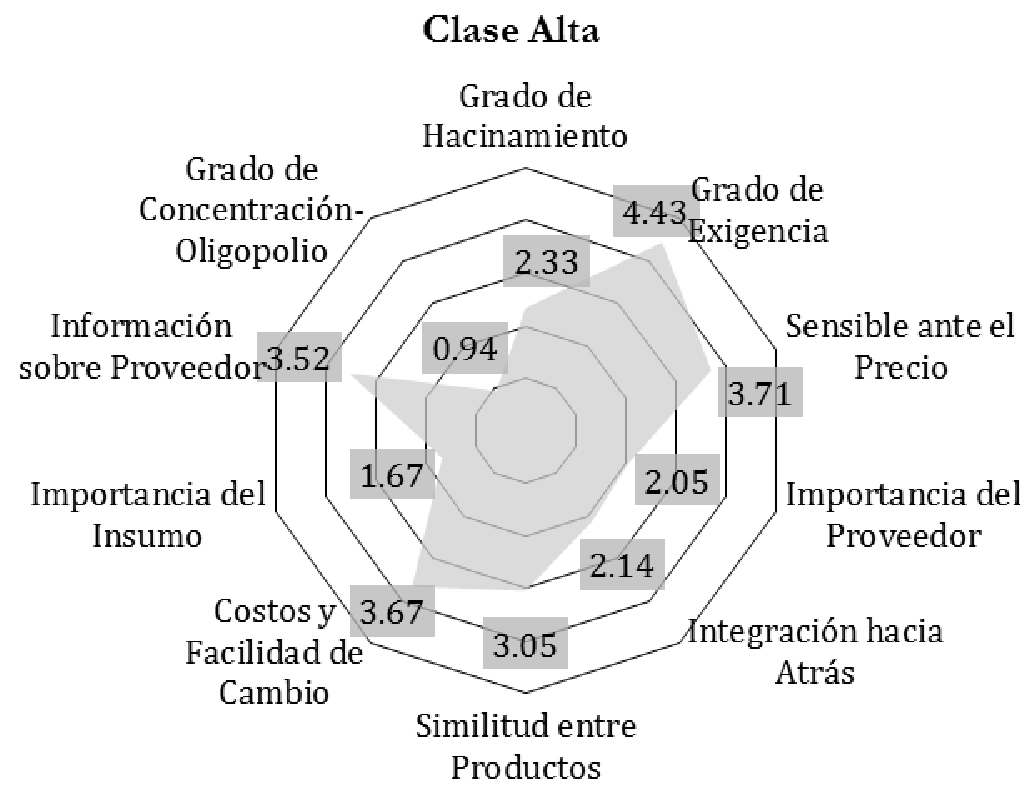

\section{Compradores}

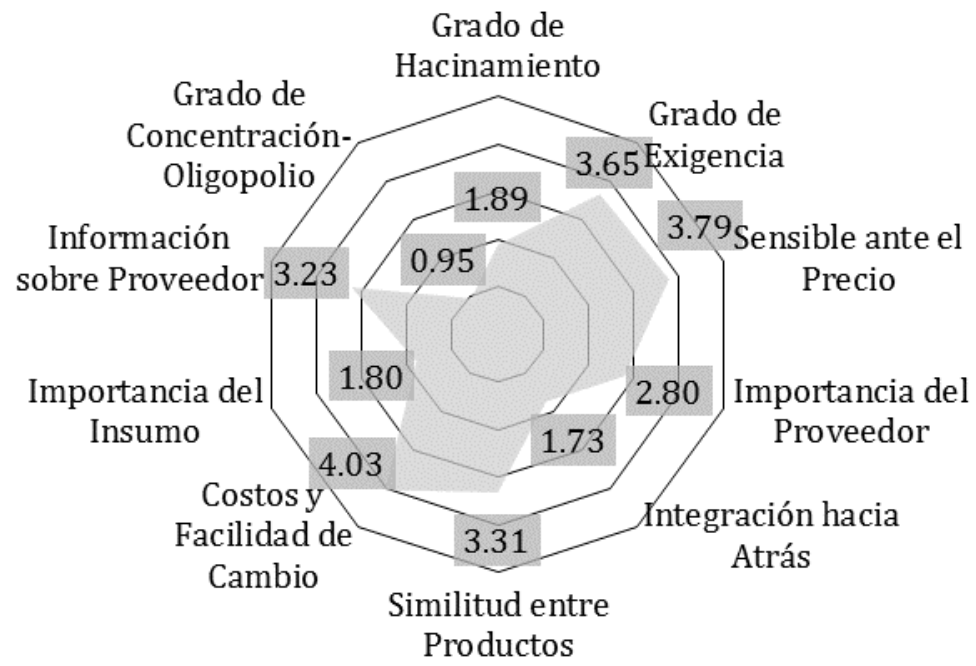

Fuente: Elaboración propia. 
La fuerza que poseen los compradores en el sector representa la segunda fuerza de mayor importancia en el sector de la promoción inmobiliaria. Esto se debe, principalmente, al poder económico que representa para el sector, porque, obviamente, no existiría un sector si no fuera por un cliente como es típico en todos los sectores de producción.

Dentro de la clase alta, la mayor fuerza la obtienen los compradores debido a sus altas exigencias. La explicación de esto yace en el hecho de que estas se construyen y terminan con materiales de lujos y se ubican en las mejores sedes de la ciudad.

Es decir, en este gremio, los clientes son exigentes y demandantes en sus terminaciones, responsabilidad y tiempo de entrega del promotor hacia ellos. Ajustándose estrictamente a recibir el producto por el cual pagaron, siendo esto sinónimo de calidad (entrega del producto con las mismas especificaciones).

Mientras en la clase media al igual que la baja tiene la mayor influencia con relación al costo y facilidad de cambio. Esta se ve marcada por el auge que hubo en construcción de viviendas en los sectores destinados a clase media; el hacimiento que presentan las empresas en estas partes de la provincia y la similitud entre los productos que ofrecen.

En resumen, lo representativo de todas las clases es esto: Grado de exigencia, costo y facilidad de cambio y sensibilidad ante el precio.

De modo que la fuerza que representa a los compradores se ve principalmente afectada por el gran poder de cambio que estas tienen ante lo proveedores. Hay un volumen de ofertas y demandas amplias, donde los compradores tienen opciones de elección no solo en cantidad, sino también en lo que concierne a los nichos son similares por distribución de espacio, precio, fachada, localización y confort. Este factor influye en la mayoría de los aspectos que definen esta fuerza, ya que por la ubicación los promotores 
suelen construir en volumen y con especificaciones muy similares. Esto implica darles elección a los compradores, de acuerdo a una zona, con precios similares y opciones variables. Estas opciones van desde la terminación, la fachada hasta el volumen de parqueos por edificio.

El factor que concierne a la sensibilidad que muestra el comprador ante los precios es el segundo aspecto que le da fuerza a los compradores. El grado de la gran inversión que está efectuando, hace que cualquier cambio en el costo sea importante para él. Esto le brinda fuerza para poder interactuar con los promotores y conseguir menores precios por medio de acuerdos de pago que van desde la compra en plano (aportando capital para los primeros pasos de la construcción), pagos progresivos o el pago total del inmueble. Estos cambios se podrían ver reflejados en un significativo porciento de rebaja para el comprador.

Esta fuerza está totalmente dominada por el aspecto económico, por ende, todo gira en torno al dinero. Según lo dicho anteriormente, la adquisición de una vivienda es una alta inversión económica y esta en general se hace de 1 a 2 veces en la vida, atendiendo a la clase económica. Es difícil por tanto generar un oligopolio en el sector por los compradores.

Por último, la calidad de vida de un ser humano hace que el producto ofertado por el sector sea de suma importancia para los compradores. Este es una necesidad de vital de todo ser humano siendo muy bajo el por ciento de personas que lo adquieren por lujo. En el país se ha vuelto un factor cultural el tener casa propia, pues los dominicanos han entendido que es mejor realizar una inversión en su propia casa, mediante préstamos hipotecarios, que pagar alquiler de viviendas durante años. Además se cuenta con una plusvalía en los inmuebles que crece cada año más. Esto le quita poder a la fuerza de los compradores. 
Luz Then, Solange Pimentel, Paola Olivero, Ailec Soto, Abraham Luna, Gilbert Crus, Miguel Peguero, Carlos Jáquez, Jorge Lluberes

\section{BARRERAS DE INGRESO}

La fuerza "Nuevo Ingreso" o "Nuevos competidores", como también se le llama busca analizar el poder que tienen los posibles nuevos competidores del sector sobre los competidores ya existentes. En otras palabras, evalúa las ventajas, facilidades y oportunidades que le dan fuerza, que benefician o ayudan a cualquier empresa promotora o promotor que quiera introducirse al sector. Un mercado es atractivo para nuevos participantes cuando las barreras de entrada son fáciles de traspasar, o sea, cuando estos pueden obtener recursos para así tomar control de una parte del mercado (Restrepo \& Rivera Rodríguez, 2008).

Para el análisis de dicha fuerza se tomaron en cuenta parámetros tales como: la facilidad para ingresar al sector; las políticas de gobierno que afectan de alguna forma a los nuevos integrantes; la inversión necesaria para ingresar al sector; los costos fijos que envuelven al sector; la relación proveedores-nuevos competidores; la facilidad de ser reconocidos por los clientes y la facilidad de innovar dentro del sector.

Figura N. ${ }^{\circ} 7$ - Riesgo de ingreso

Nuevos competidores

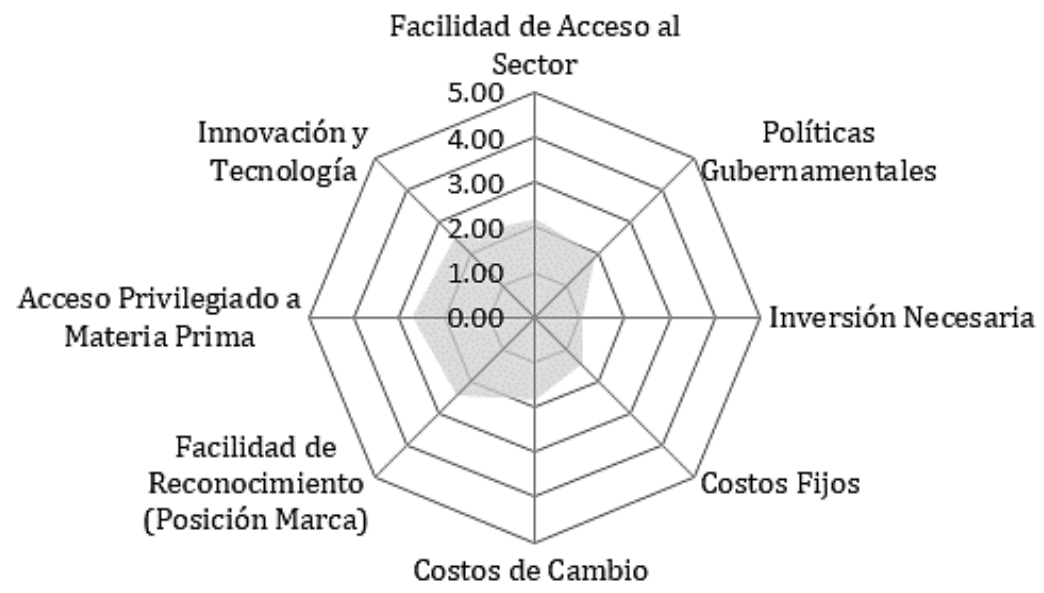

Fuente: Elaboración propia. 
Como se dijo anteriormente, se evaluó el comportamiento de las fuerzas para las diferentes clases sociales a las que se dirige el sector. Para los nuevos integrantes, el comportamiento dentro de las clases fue básicamente el mismo; es decir que seguían la misma tendencia con una diferencia numérica despreciable.

Lo que más fuerza le brinda a los nuevos competidores es la relación proveedor-competidor del sector. En la actualidad lo que importa es la venta, las nuevas empresas tienen facilidad de obtener buenos tratos y acuerdos con los proveedores.

Después del acceso a materia prima hay que destacar que existen dos parámetros que les dan fuerza a los nuevos integrantes: nos referimos a la facilidad de innovar y hacerse reconocer dentro del sector. Según las encuestas realizadas, no es difícil ingresar al sector con un producto innovador. El reconocimiento en el sector depende, principalmente, de la publicidad, dígase, aparecer en revistas y páginas web inmobiliarias, vallas publicitarias, entre otros medios. Luego de esta primera acción de reconocimiento, los primeros clientes suelen expandir esta publicidad, basándose en su satisfacción y experiencia, creándole a la empresa una posición de marca.

Hay parámetros que significan un desafío para un nuevo competidor. Tratándose del sector de promoción inmobiliaria, la inversión necesaria es el protagonista. El capital necesario para ingresar al sector es alto ya que el producto es un proyecto inmobiliario. Esto provoca que las empresas tengan índices de rentabilidad negativos debido a la gran inversión de capital necesario y al poco ingreso que se obtiene durante el desarrollo del proyecto, ya que se convierte en un ingreso al momento de la entrega del inmueble.

En un sentido similar afectan los costos fijos a los nuevos competidores. Los costos fijos necesarios para mantener una empresa funcionando son medio altos; dígase, empleados fijos, servicios, mantenimiento de oficina, etc. Lo que se traduce en un desafío para las nuevas empresas debido a que deben mantener la compañía funcionando sin necesariamente estar produciendo. 
Salir del sector no es muy fácil tampoco. Entre trabas contractuales que se pueden encontrar y los impuestos se generan unos costos medio altos que hay que tomar en cuenta. Aunque se ha observado que se está haciendo un esfuerzo por cambiar esto. La Norma General N. ${ }^{\circ}$ 07-2007 es uno de ellos.

El tema de las políticas gubernamentales no es una preocupación exclusiva de los nuevos competidores. No existen leyes que afecten a los nuevos integrantes del sector específicamente. El sector de promoción inmobiliaria dominicano está poco regulado y controlado, lo que les brinda una facilidad de entrada a los nuevos integrantes. Incluso hay regulaciones que benefician a los nuevos integrantes sobre competidores ya existentes.

"Para los proyectos nuevos, de empresas recién constituidas, las normas son mucho más flexibles, y permiten a las entidades de Intermediación Financiera otorgar la clasificación "B", que otorga a los proyectos de inversión para la estimación de la capacidad de pago, siempre y cuando se haga constar que los mismos, cuentan con un estudio de factibilidad que demuestra su viabilidad." (Castillo Polanco, 2013). Esto se traduce en una ventaja de los nuevos competidores en el tema de financiación.

\section{PRODUCTOS SUSTITUTOS}

Con esta fuerza se busca determinar el grado de amenaza de los productos sustitutos para el sector estratégico. Se analizan las alternativas de los productos que podrían reemplazar los ya ofrecidos por el sector.

"Ser parte de la situación de que un mercado no es atractivo si existen productos sustitutos reales o potenciales. Todo se complica si los sustitutos están más avanzados tecnológicamente o pueden entrar con precios más bajos, reduciendo los márgenes de utilidad de la empresa, afectando la estabilidad del precio de venta en el mercado" (Restrepo \& Rivera Rodríguez, Análisis Estructural de Sectores Estratégicos, 2008). 
Análisis de las Fuerzas Competitivas de Porter en el sector de promoción inmobiliaria del Gran Santo Domingo

\section{Figura N. ${ }^{\circ} 8$ \\ Productos sustitutos}

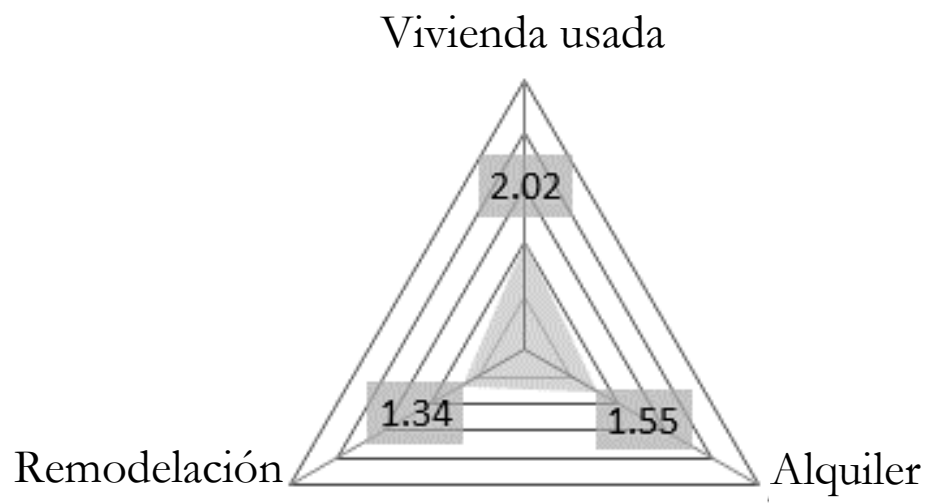

Fuente: Elaboración propia.

“...El diez por ciento de la demanda real de viviendas es para fines de alquiler, lo que ofrece señales de un segmento de mercado que podría dinamizar el sector de la construcción de viviendas." -Francisco Gonzales (Acosta \& Ircania, 2013). En otras palabras, el alquiler, aunque teóricamente puede considerarse como un sustituto de la venta, es una amenaza solamente transitoria y temporal sobre el sector de promoción de inmuebles nuevos. Esto se debe a que, como inversión, las personas tienden a comprar inmuebles nuevos para destinarlos al negocio de la renta. Debido a un factor cultural, en nuestro país el alquiler de inmuebles y la compra de viviendas usadas, no es considerado un sustituto de lo que significa una vivienda nueva. Mas bien se considera otra necesidad, otro nicho de mercado. Vale la pena destacar que este comportamiento tiene esta tendencia porque actualmente el mercado está regularizado por tasas relativamente bajas. Cuando las tasas de interés incrementan en un 20-30\%, estos pasan a ser una real e importante amenaza para el sector de la promoción de viviendas nuevas. 
Luz Then, Solange Pimentel, Paola Olivero, Ailec Soto, Abraham Luna, Gilbert Cruz, Miguel Peguero, Carlos Jáquę, Jorge Lluberes

\section{PODER DE LOS PROVEEDORES}

"El sector de los proveedores está liderado por 5 principales empresas que manejan el 90\% de las provisiones de mercancías a obras". (Según William Crespo). Debido a la alta concentración en el mercado de empresas existentes, y a la facilidad que tienen los clientes de cambiar de proveedores, estos deben de brindar el mejor servicio a sus clientes, ya que con tan solo un descuido basta para que el proveedor pierda a un cliente. El precio de los productos ofertados por los proveedores tiene poca variación, sin embargo el elemento diferenciador es la calidad que estos ofrecen; esto les quita fuerzas a los proveedores sobre sus clientes. De manera general no existe oligopolio entre los proveedores a excepción de dos mercados, la varilla y el cemento, en el caso de la varilla está regido solo por dos empresas y mercado del cemento cuenta con una asociación con el fin de no diversificar un producto extranjero en el mercado.

\section{Figura N. ${ }^{\circ} 9$ \\ Poder de los proveedores}

\section{Proveedores}

Nivel de Importancia del Insumo

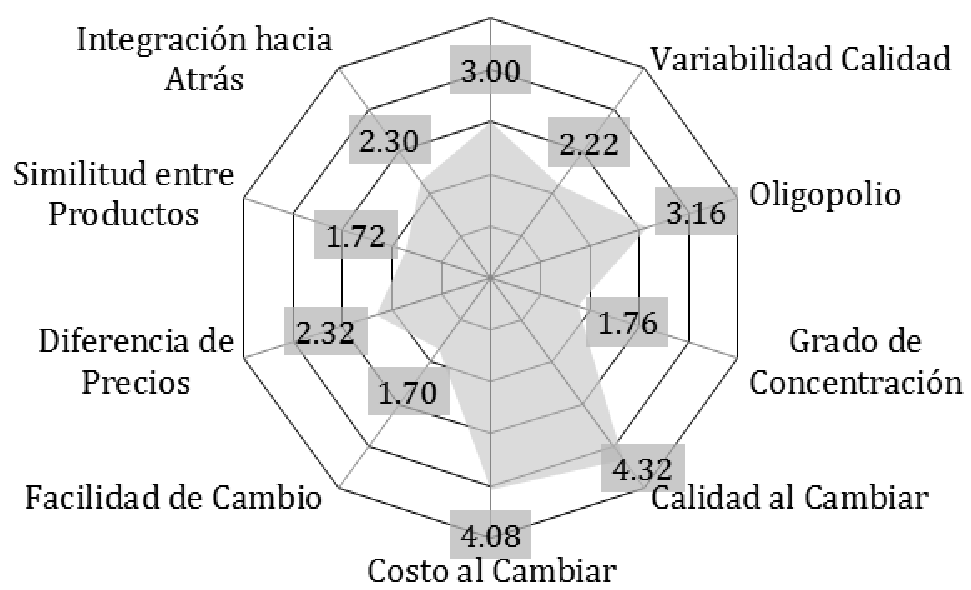

Fuente: Elaboración propia. 
El costo es un factor que depende primordialmente de la clase social con la que se está trabajando. En el caso de la clase baja, el costo es muy importante, debido a que el cliente compra los productos a menores costos, sin importar la calidad del mismo; esto le quita fuerza al proveedor sobre sus clientes y le da menos poder de negociación. En el sector de la clase media y alta, el costo no importa tanto, siempre y cuando se cumpla los estándares de calidad requerido por el cliente para su obra. Esto le da fuerza y poder de negociación al proveedor sobre su cliente.

\section{MANO DE OBRA}

La mano de obra es un aspecto del sector que afecta directamente la rentabilidad del proyecto, la calidad y el costo, ya que es básicamente un servicio que se provee, es necesario mencionarlos dentro de lo que son los proveedores.

Empecemos primero por describir los rasgos de la mano de obra que amenazan o influencian el sector de alguna manera:

1) El 30\% de los costos de un proyecto se derivan de errores o improductividad de la mano de obra. (The Economist). Esto ocurre en primera instancia por el hecho de que en, su gran mayoría, los obreros son personas que cuentan meramente con un nivel educativo primario, ni hablar de alguna preparación técnica. En nuestro país, las habilidades se generan con la experiencia.

2) Los trabajos generados por el sector son de naturaleza temporal, régimen contemplado dentro de las modalidades del contrato de trabajo como tipo 2. En caso de que no se excedan los cuatro meses, no existe ninguna responsabilidad para las partes. Esto ha provocado "una insostenible situación económicolaboral para los promotores y constructores, no solo por la carga social aludida que representa la nómina de empleados permanentes, sino también por la plataforma de capacitación creada por algunos profesionales del derecho dedicados al 
reclutamiento de demandas sin soporte legal, derivando en un alto costo para las empresas demandadas." (Castillo, 2013). Estas prácticas, además de todo, no ayudan al bienestar del trabajador ya que al final terminan pagando honorarios y costo procesal. Todo esto se resume en la necesidad de un código laboral que satisfaga la realidad social de lo que es el sector.

3) La legislación que exige que un porcentaje de la mano de obra sea dominicana. Al final, termina siendo un costo mayor para el promotor ya que la mano de obra extranjera tiende a ser más barata que la nacional.

4) El 57\% de la actividad laboral es de trabajo informal. (Acoprovi, 2013). Esto se traduce en desafíos legales, contractuales, de migración, de seguro social y de salud.

Instituciones como Acoprovi, tratando de remediar estas problemáticas han puesto en marcha acciones de mejora y solución. Entre estas se encuentra el curso de capacitación de plomeros que se hizo mediante un acuerdo con la CAASD e INFOTEP.

\section{COMPLEMENTARIOS}

Al evaluar la competitividad de un sector, los analistas sienten la necesidad de estudiar varios atributos del sector. El papel que juegan estos depende del sector analizado. (Porter, 2007).

En su artículo "Entendiendo la Estructura de la Industria", Porter considera 4 atributos generales: Tasa de crecimiento del sector; gobierno; tecnología e innovación; y el rol de productos y servicios complementarios. Tomando estos como base y los comentarios de las personas encuestadas y entrevistadas, llegamos a la decisión de considerar el rol del gobierno y la banca como una sexta fuerza llamada complementarios debido a que estos dos actores son complementos del servicio y el producto que brinda el sector analizado. Sin la banca, no hay venta de producto y sin el gobierno no es posible 
producirlo. Estos afectan la demanda y la oferta del producto. Vale la pena destacar que, aunque Porter se refiere a un complementario como un producto o servicio que solo le agrega valor o impacta positivamente al sector, en nuestro caso, no es lo que sucede.

\section{EL GOBIERNO}

Desde inicios de su mandato, el presidente Danilo Medina ha demostrado gran preocupación por lo que es el tema de la vivienda, en general. Aun así, queda mucho trabajo por delante. Se necesita incentivar el sector de promoción inmobiliario para atacar el déficit habitacional que hoy nos afecta. La puesta en marcha de la Ley 189-11 para el desarrollo del mercado hipotecario y fidecomiso y el proyecto Ventanilla Única han sido de gran ayuda; solo hace falta un poco más de aporte para terminar de eliminar las importantes barreras gubernamentales que impiden el mero desarrollo del sector de promoción inmobiliaria y los sectores ligados a este. A continuación se mencionarán los aspectos que se traducen en barreras para nuestro sector:

- La carencia de un Plan de Urbanización Nacional actualizado y un organismo que defina este plan regulador de ciudades con el objetivo de dotar a las familias dominicanas de acceso a la vivienda. Una posible solución a este problema sería la propuesta por la arquitecta Claudia Castillo, según lo expuesto en su artículo "Necesidad del Ministerio de Vivienda y Urbanismo", publicado en la revista de Acoprovi.

- Aunque se cuenta con una estructura que promete ser funcional en las instituciones que administran o involucran a importantes herramientas para el sector, la realidad es otra. Las diferentes instituciones públicas que se encargan de los trámites requeridos para concretizar un proyecto, como lo son el ministerio de obras públicas, medio ambiente y registro de títulos, necesitan de empleados más honestos y capacitados para hacer su trabajo. 
El insólito agobio que significan tramitar los permisos y certificaciones, el costo que a estos envuelven y la facilidad que tienen aquellos de flexibilizar el sistema de control y seguimiento gubernamental para auto-beneficiarse, siguen siendo una grave barrera para aquellos que participan dentro del sector.

\section{LA BANCA}

El servicio de la banca es indispensable para que nuestro producto sea producido y consumido. Es por esto que la banca se debe analizar desde dos puntos de vista:

- La banca como fuente de recursos que ayuda a financiar un proyecto.

- La banca como entidad que ayuda al cliente a adquirir el proyecto.

COMO FUENTE DE RECURSOS QUE AYUDA A FINANCIAR EL PROYECTO

"Cuando un proyecto de desarrollo inmobiliario requiere de financiamiento, las empresas constructoras suelen encontrarse de entrada con la dificultad de que su clasificación conforme a las normativas y regulaciones bancarias vigentes, les limita el acceso al crédito." (Polanco, Razones que Obstaculizan la Calificación de Riesgo Favorable de las Empresas Constructoras para la Obtención de Financiamiento, 2013). Esto quiere decir que las vías tradicionales de obtención de crédito representan una dificultad para las empresas que compiten en el sector, ya que deben buscar otras formas de financiar su proyecto u optar por no desarrollarlo. Vale la pena destacar que hay más flexibles para empresas recién constituidas y que las empresas ya existentes que califiquen pueden optar por aprovechar la ley 189-11. Para atacar el problema que afecta al resto del sector, son necesarios mecanismos que se adapten al sector y a sus irregularidades. Entre estas irregularidades se encuentran el poco ingreso que se capta durante el desarrollo del proyecto, su extenso ciclo operativo, y los altos índices de endeudamiento. 
"En República Dominicana a pesar de que existen iniciativas aisladas de diferentes instituciones, lamentablemente, no contamos con un programa formal de bancarización, que es una tarea importante y urgente para mejorar el bienestar de los hogares dominicanos, otorgándoles la posibilidad de acceder a sistemas de pagos y ahorros muchos más seguros y eficientes, así como también atender las necesidades de créditos, en especial la de obtención del principal bien familiar, la compra de una vivienda." (Polanco, Necesidad de Bancarización en la Republica Dominicana, 2013). Básicamente, el bajo nivel de bancarización es el principal problema que se manifiesta en la relación Banca-Sector Promoción Inmobiliaria. Definimos bancarización como el acceso que tiene la población a servicios financieros múltiples y diversos.

Si se toma en cuenta el hecho de que ya hay tres instituciones bancarias que ofrecen "la cuenta de ahorro programada" y tasas fijas por 6 años, se podría decir que dentro de este macro-problema, el punto que merece mayor énfasis es lo relacionado con la carencia de una estructura de financiamiento dirigida a personas que no tengan un background económico, dígase, personas informales. Pensando en el déficit de viviendas de bajo costo que existe en la actualidad, podría decirse que esta es una gran desventaja para el sector.

A modo de resumen, la banca y las instituciones gubernamentales limitan el sector de promoción inmobiliaria, ya que son una retranca. Existen puntos de mejora en la relación banca-gobiernosector de promoción inmobiliaria que son necesarios atacar, ya que son las principales razones por las cuales se considera que el sector promoción inmobiliario de la República Dominicana es aún un sector sin explotar esperando a ser aprovechado. 
Luz Then, Solange Pimentel, Paola Olivero, Ailec Soto, Abraham Luna, Gilbert Crus, Miguel Peguero, Carlos Jáquez, Jorge Lluberes

Figura N. ${ }^{\circ} 10$

Cinco fuerzas competitivas de Porter

Nuevo

Competidor

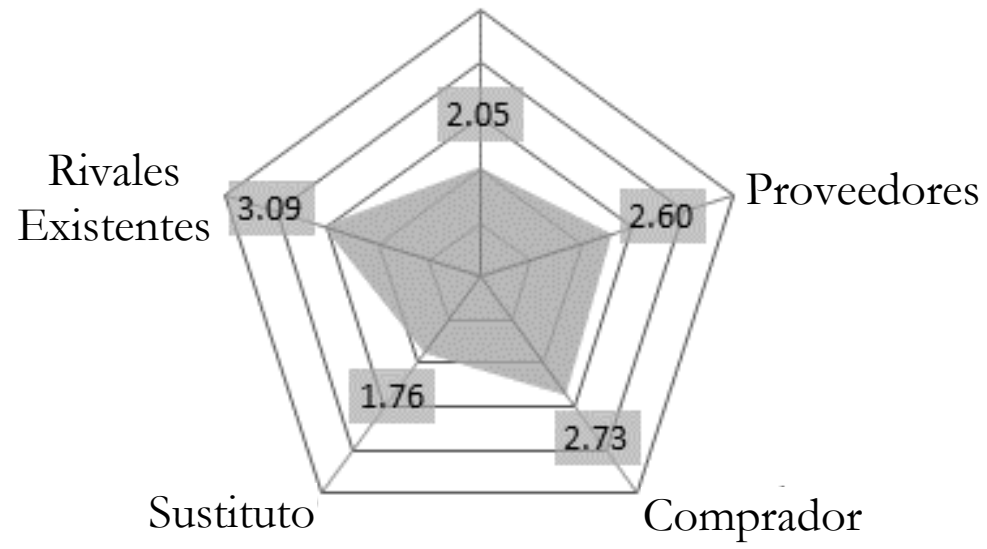

Fuente: Elaboración propia.

El modelo de las cinco fuerzas de Porter propone un marco de reflexión estratégica y sistemática para determinar la rentabilidad de un sector en específico, normalmente con el fin de evaluar el valor y la proyección futura de empresas o unidades de negocio que operan en dicho sector.

Como puede mostrarse en las gráficas siguientes, la mayor fuerza del sector se debe a la rivalidad entre competidores existentes. Por lo tanto, se debe implementar estratégicas siendo lo primordial elaborar "una propuesta de valor única para los clientes.

Los factores con más relevancias y que generan la alta competitividad en el sector son: primero, la presencia de grandes empresas, en un segundo lugar, el nivel de concentración que se efectúa en una misma zona y, finalmente, están los costos fijos que posee una compañía donde las compañías, en general, reciben un duro impacto de las grandes empresas, ya que estas cuentan con capital suficiente, o sea, tienen estrategias de producción en masa, integración hacia atrás. 
A sabiendas de que se pierde competitividad a través de la poca diferencia que existe entre los productos ofertados atendiendo a cada clase. También se afecta el lento crecimiento de clientes, pues de manera global hay una la crisis mundial y los precios para adquirir este tipo de insumo son bien característicos. Por último, hay que tomar en cuenta los niveles de producción, puesto que en la construcción cada proyecto es único haciendo difícil establecer una estandarización y empezar a producir en masa.

Luego, tenemos el poder de negociación de los compradores o clientes. La misma está marcada a favor del comprador mediante los costos y facilidades de cambios que hay en el sector, y estas se deben a la similitud de los productos y al hecho de que pueden encontrarse en una misma zona. En ese orden de ideas, hay que tener en cuenta la sensibilidad que muestra el cliente ante el precio, ya que cualquier alteración en el mismo resulta significativa para él. Entre los aspectos importantes que deben tenerse en cuenta está el grado de exigencia relacionado con la calidad en las terminaciones y el tiempo de entrega.

Pero aplicando el dualismo a esta fuerza, queda dramáticamente afectada porque los compradores no pueden generar un oligopolio en el mercado. También, se ve casi imposibilitado a realizar una integración hacia atrás. Ya que a fin de cuenta no es un producto de "hágalo usted mismo". Y por último, pero no menos importante por razones sociales y de calidad de vida, está la razón indispensable del producto, ya que, a corto o largo plazo de su vida es una necesidad que termina beneficiando al proveedor.

Hay que destacar el poder de negociación de los proveedores o vendedores. La influencia de este segmento del sector se diferencia en la calidad, ya que los costos suelen ser muy parecidos por la gran cantidad de empresas que suplen los insumos. Luego le sigue el costo el cual es muy valorado por contratistas y promotores para elegir a sus proveedores. Asimismo contando a su favor el nivel de importancia que puede tener el insumo que suplen en un 
Luz Then, Solange Pimentel, Paola Olivero, Ailec Soto, Abraham Luna, Gilbert Crus, Miguel Peguero, Carlos Jáquez, Jorge Lluberes

determinado período de tiempo, ubicaciones, especificaciones, leyes, entre otras. Cabe destacar, que de manera general hay dos mercados que rigen como un oligopolio al sector promoción inmobiliaria: son la varilla y el cemento.

En los mercados que no tienen oligopolio hay una gran variedad de productos similares con las mismas especificaciones técnicas y otros que cumplen lo deseado, siendo un producto sustituto "como muros de block a muro de foam".

La tendencia con la amenaza de nuevos entrantes al sector. La facilidad de reconocimiento que puede tener una compañía en sus inicios, la obtiene a través de elementos publicitarios; a esto se suma las ventajas que puede ofrecer a los proveedores ya que estos cada día buscan más compradores. El único beneficio difícil de adquirir por parte de un nuevo competidor, en este sentido, son grandes líneas de créditos y tiempos de pago. Al final tenemos el ingreso al sector con un producto único, porque al existir en el mercado tanta similitud, de acuerdo a la clase, algo diferente es un acontecimiento de relevancia a destacar y que conduce al comprador a una rápida decisión hacia este inmueble.

No obstante, contiene elementos fuertes a superar como son la inversión necesaria para entrar al sector. Luego tenemos los costos de cambio hacia otro sector, por el tema de los impuestos, leyes y pagos a los empleados. Finalmente, los costos fijos para mantener en funcionamiento la empresa, ya que hay ciertos momentos en que se requiere de un personal sin tener obras en cartera.

La menor influencia en el sector está relacionada con la amenaza de productos sustitutos. La mayor afectación que tiene el sector es la realización de compras de viviendas usadas, seguidas por el alquiler y, en última instancia, la remodelación.

A pesar de todo, el alquiler de viviendas se considera como una amenaza transitoria y temporal sobre el sector de promoción de 
inmuebles nuevos. Los promotores suelen no considerar un sustituto de lo que significa una vivienda nueva. Es más bien considerada otra necesidad, otro nicho de mercado.

$\mathrm{Al}$ final hemos creado una herramienta de análisis para evaluar y conocer la situación actual del sector promotor inmobiliario. El análisis mostrado quiere conducirnos a una conducir a una reflexión certera, exhibiendo el nivel de atracción del mismo para los nuevos inversionistas; además, los inconvenientes que pueden presentarse al querer entrar, mantenerse y salir del sector.

\section{Recomendaciones}

Se recomienda sobre la base de las conclusiones anteriores, la utilización de esta herramienta. La misma que ha sido creada con el fin de brindar una información actualizada, validada y de confiabilidad con relación a las fuerzas que afectan el sector. Con esta podrán realizar una estrategia que les permita obtener ganancias, calidad y crear productos innovadores.

Además, exhortamos a los promotores del sector a hacer una investigación correcta de mercado antes de iniciar un proyecto, con el fin de satisfacer una demanda que asegure el éxito del proyecto.

Tal como se ha planteado son necesarias las mejoras en el ámbito banca y gobierno. Hay que tomar acción vinculada con el plan de urbanización nacional, controles gubernamentales más serios, organización de las instituciones gubernamentales, facilidades de financiación para los promotores y el pueblo dominicano; entre otros aspectos; ya que en la mejora de muchos de estos ámbitos subyace la dinamización del sector. 
Luz Then, Solange Pimentel, Paola Olivero, Ailec Soto, Abraham Luna, Gilbert Cruz, Miguel Peguero, Carlos Jáquez, Jorge Lluberes

\section{Referencias bibliográficas}

Asociación Dominicana de Construcciones y Promotores de Viviendas. (2012). Estudio de oferta y demanda de viviendas en zonas urbanas de República Dominicana. Santo Domingo: Asociación Dominicana de Construcciones y Promotores de Viviendas.

Asociación Dominicana de Construcciones y Promotores de Viviendas. (2013). Tercera Mesa. Boletin Informativo 05 de Acoprovi. Recuperado de http://acoprovi.org/

Acosta, C., \& Ircania, V. (2013, 06 de mayo). Estudio: 143,000 buscan vivienda. Listín Diario.

Aranaga, B. G. (2009). Estudio de mercado: Sector construcción e inmobiliario en República Dominicana. Santo Domingo: Cámara Oficial de Comercio e Industria República Dominicana.

Cámara de Madrid. (2009). Estudio de mercado: sector construcción e inmobiliario en República Dominicana (pp. 2-8). Madrid: El Autor.

Castillo, I E. (2013). Código laboral dominicano y su influencia en la construcción habitacional. Boletin 05 Informativo de Acoprovi, (s.p.)

Ehmke, C., Fulton, J., Akridge, J., Erickson, K., \& Linton, S. (2004). Industry analysis: The Five Forces. Recuperado de https://www.extension.purdue.edu/extmedia/EC/EC-722.pdf

Gómez, J. H., Méndez, L. S., \& Rivera Rodríguez, H. A. (2010). Manual para la realización del análisis de las fuerzas del mercado en pymes. Bogotá: Universidad del Rosario.

Leroux, G. F. (2012). Análisis del informe Doing Business 2013: El caso de la República Dominicana. Washington: Corporación Financiera Internacional del Banco Mundial. 
Öney-Yazýcý, E., \& Acar, E. (2006). Competitive micro environment of small residential building contractors. 1st International CIB Endorsed METU Postgraduate Conference. Ankara: Built Environment \& Information Technologies.

Peredo Rojas, G. A., \& Peralta Bidó, S. (2004). Estudio integral del sector de la construcción. Santo Domingo: United Nations Conference on Trade and Development.

Polanco, D. L. (2013). Necesidad de bancarización en la República Dominicana. Boletin Informativo de Acoprovi 06, 36-46.

Polanco, D. L. (2013). Razones que obstaculizan la calificación de riesgo favorable de las empresas constructoras para la obtención de financiamiento. Boletín Informativo de Acoprovi, 8-9.

Porter, M. E. (2007, 13 de agosto). Understanding Industry Structure. Harvard Business School (s. p.).

Porter, M. E. (2008, enero). Las cinco fuerzas competitivas que le dan forma a la estrategia. Recuperado de http://es.slideshare.net/ alan_gp13/cinco-fuerzas-de-porter-22986802

Restrepo, L. F., \& Rivera, H. A. (2008). Análisis estructural de sectores estratégicos. Bogotá: Universidad del Rosario.

Rivera Rodríguez, H. A., Hernán Gómez, J., \& Sofía Méndez, L. (2010). Manual para la realización del análisis de las fuerzas del mercado en pymes. (Documento de Investigación N. ${ }^{\circ} 72$ ). Bogotá: Universidad del Rosario. 
Luz Then, Solange Pimentel, Paola Olivero, Ailec Soto, Abraham Luna, Gilbert Crus, Miguel Peguero, Carlos Jáquez, Jorge Lluberes

\section{Luz Then}

Actualmente labora en la Constructora LALPE y se desempeña en el área de administración de la construcción.

Email: luz.carolina.then@gmail.com

\section{Solange Pimentel}

Es egresada de Ingeniería Civil del Instituto Tecnológico de Santo Domingo. Actualmente forma parte de la empresa Pimentel Piña y Ascos., S.A. Email: solpim@hotmail.com

\section{Paola Olivero}

Es egresada de Ingeniería Civil del Instituto Tecnológico de Santo Domingo, INTEC. Actualmente es asistente de Ingeniería, CADIPRECO, S.R.L. Email: olivero.paola@gmail.com

\section{Ailec Soto}

Es egresada de Ingeniería Civil del Instituto Tecnológico de Santo Domingo.

Email: ailecsotogarabito@gmail.com 


\section{Abraham Edmundo Luna Barriola}

Graduado Cum Laude de Ingeniería Civil en el Instituto Tecnológico de Santo Domingo. $\mathrm{Ha}$ participado en diversos diplomados relacionados con la Ingeniería como el de Presupuesto y Licitación de Obras y Administración de la Construcción. Actualmente labora como encargado de Proyectos para la empresa Crux de Luna Constructora Inmobiliaria.

Email: aluna0522@gmail.com

\section{Gilbert Cruz}

Es egresado Ingeniería Civil del Instituto Tecnológico de Santo Domingo (INTEC). Actualmente trabaja para la Constructora: C. H. Ingeniería y Proyectos, S. R. L.

Email: gil9224@hotmail.com

\section{Miguel Peguero}

Es egresado de Ingeniería Civil del Instituto Tecnológico de Santo Domingo (INTEC).

Email: miguel_peguero17@hotmail.com

\section{Carlos Rafael Jáquez Castillo}

Es graduado de Ingeniería Civil e Ingeniería Mecánica del Instituto Tecnológico de Santo Domingo. Actualmente se desempeña como vicepresidente de Inversiones y Construcciones del Caribe.

Email:cajaquez@gmail.com 
Luz Then, Solange Pimentel, Paola Olivero, Ailec Soto, Abraham Luna, Gilbert Cruz, Miguel Peguero, Carlos Jáquez, Jorge Lluberes

\section{Jorge Arturo Lluberes}

Es egresado de ingeniería Civil del INTEC y estudiante de término de Ingeniería Industrial dentro del mismo recinto. Es ingeniero residente de la Constructora VECK y Asociados.

Email: jorge_lluberes@hotmail.com

Recibido: 05/04/2014 Aprobado: 25/08/2014 